effect a more rapid and complete metabolism in which the former $\mathrm{C}_{4}$ products are incorporated into citrate so that less acetate is available for conversion to oxalate.

Other aspects of this work will be reported elsewhere.

Courtauld Institute

Middlesex Hospital,

London, W.1. Jan. 16.

${ }^{1}$ Walker, T. K., Hall, A. X., and Hopton, J. W., Nature, 168, 1042 (1951).

${ }^{2}$ Lugg, J. W. H., and Overell, B. T., Nature, 160, 87 (1947); Aust. J. Sci. Research, A, 1, 98 (1948).

${ }^{3}$ Cavallini. D., Frontali, N., and Toschi, G., Nature, 163, 568; 164, $792(1949)$.

4 Taussky, H. H., and Shorr, E., J. Biol. Chem., 169, 103 (1947).

' Halliwell, G., Anal. Chem., 22, 1184 (1950).

- Currie, J. N., J. Biol. Chem., 31, 15 (1917).

"Challenger, F., Subramaniam, V., and Walker, T. K., J. Chem Soc., 200, 3044 (1927).

${ }^{8}$ Lynen, F., and Jynen, F., $A n n ., 560,149$ (1948)

- Deniges, G., Ann. chim. Phys., 18, 178 (1909). Neuberg, C., Biochem. Z., 24, $436(1910)$.

${ }^{10}$ Sakaguchi, K., and Baba, S., J. Agric. Chem. Soc. Japan, 18, 1127 (1942).

\section{Paper Chromatography of Natural Resins}

APART from an early attempt by Stock $^{1}$ to adapt a method of capillary analysis on filter paper for the examination of natural resins, the potentialities of the chromatographic technique in this field do not seem to have been investigated. The present communication deals with the application of paper partition chromatography to the identification of natural resins and the separation of the constituents present, with particular reference to dammar and mastic. It has been found that such a separation can be readily achieved in a reversed-phase system using odourless kerosene (boiling range $180^{\circ}-200^{\circ}$ C.) as the stationary phase on the filter paper and aqueous iso-propanol saturated with odourless kerosene as the mobile phase. The filter paper strips (Whatman No. 1) are impregnated by dipping them in a 25 per cent solution of odourless kerosene in ether, excess solution being removed by pressing between sheets of filter paper. About $0.2 \mathrm{mgm}$. of the resin dissolved in acetone or chloroform is spotted at the origin, and a descending chromatogram is run at $21^{\circ} \mathrm{C}$. using the lower phase of the system iso-propanol $(7.5$ parts $)$ water $(2.5$ parts $)$ and odourless kerosene (1 part) as solvent. (For the faster-moving spots a better separation is achieved using 6.5 parts of isopropanol.) The solvent front moves slowly, usually about $25 \mathrm{~cm}$. in twenty-four hours; but the actual distance may vary with slight changes in the experimental conditions. The strips are dried, and the chromatogram is developed by spraying with a fifty per cent $(w / v)$ solution of phenol in carbon tetrachloride and exposing to bromine vapour for a short period. Those resin components which give a positive Halphen-Hicks test ${ }^{2}$ are shown up as coloured zones normally varying in hue from pink to violet, but with certain resins blue or yellow zones appear. These colours fade rapidly if left exposed to the air, but will remain fairly bright for about a week if the strips are kept in a closed box.

Each of the resins so far tested, namely, dammar, mastic, sandarac, rosin, elemi and copal, gives a characteristic chromatogram, which may be distinguished by virtue of the number, colour and $R_{F}$ values of the coloured zones. As a typical example we reproduce in the accompanying photograph the chromatogram given by dammar. The slowestmoving spot is due to the $\beta$-resene component of dammar, but the remaining zones have not yet been identified as corresponding to the other constituents of dammar described in the literature. Although this system constitutes a reliable test for the identification of individual resins, it has been primarily developed as a convenient method for following the course of larger-scale separations on an alumina column of the components of dammar and mastic resins. The results of this work will be published elsewhere.

This investigation is part of a programme of work which has been rendered possible by a grant from the Nuffield Foundation to Mr. F. I. G. Rawlins. One of us (J. S. M.) is indebted to the same Foundation for the award of a scholarship.

J. S. MrLls

A. E. A. WERNER

National Gallery;

London, W.C.2.

Maý 5.

${ }^{1}$ Stock, E., Farb.-Z., 31, 1903 (1927).

${ }^{2} J$. Indust. Eng. Chem., 3, 86 (1911).

\section{Release of Histamine from Rat Diaphragm by Cobra Venom}

Several substances like strychnine, adrenaline and curare alkaloids are known to set free histamine from skeletal muscle. The release of histamine from rat diaphragm by ammonia ${ }^{1}$ and $D$-tubo-curarine chloride $^{2}$ has recently been reported. Feldberg and Kellaway ${ }^{3}$ have shown that snake poisons liberate histamine from the perfused lungs of guinea pigs and cats. 'The experiments described here demonstrate that cobra (Naia naia) venom is a potent liberator of histamine from striated muscle of the rat.

A portion of the rat diaphragm was placed in $5 \mathrm{ml}$. oxygenated warm $\left(37^{\circ} \mathrm{C}\right.$.) Tyrode solution, while a similar part of the muscle was immersed in the same way in Tyrode solution containing different concentrations of cobra venom. These solutions were replaced by fresh ones every five minutes. The active substance released from the muscle by the snake venom stimulated guinea pig's intestine suspended in Tyrode solution like histamine. The contractions produced by the liberated substance and matched doses of histamine were reduced almost to an equal degree by 'Antistin' (CIBA) and 'Benadryl' (P and D) but were unaffected by atropine. The active agent was therefore either histamine or a substance very similar to it. The liberated histamine was estimated biologically on isolated guinea pig's ileum suspended 